\title{
Correction: comparing single-site with multisite rTMS for the treatment of chronic tinnitus - clinical effects and neuroscientific insights: study protocol for a randomized controlled trial
}

\author{
Astrid Lehner ${ }^{*}$, Martin Schecklmann, Peter M Kreuzer, Timm B Poeppl, Rainer Rupprecht and Berthold Langguth
}

\section{Correction}

Following publication of our article [1], we became aware that the treatment protocol for the single-site group is incorrectly stated in the methods section. All patients in this group are stimulated over the left temporoparietal cortex (not over the temporoparietal cortex contralateral to the tinnitus percept). Using the same stimulation site for all patients in the single-site group avoids the otherwise subsequently necessary division into (possibly dysbalanced) subgroups and hence ensures straightforward data analyses and interpretability, especially with respect to the longitudinal imaging data.

Received: 16 April 2014 Accepted: 17 April 2014

Published: 27 April 2014

\section{Reference}

1. Lehner A, Schecklmann M, Kreuzer PM, Poeppl TB, Rupprecht R, Langguth B: Comparing single-site with multisite rTMS for the treatment of chronic tinnitus - clinical effects and neuroscientific insights: study protocol for a randomized controlled trial. Trials 2013, 14:269.

doi:10.1186/1745-6215-15-148

Cite this article as: Lehner et al:: Correction: comparing single-site with multisite rTMS for the treatment of chronic tinnitus - clinical effects and neuroscientific insights: study protocol for a randomized controlled trial. Trials 2014 15:148.

* Correspondence: Astrid.Lehner@medbo.de

Department of Psychiatry and Psychotherapy, University of Regensburg,

Universitaetsstraße 84, Regensburg 93053, Germany

Submit your next manuscript to BioMed Central and take full advantage of:

- Convenient online submission

- Thorough peer review

- No space constraints or color figure charges

- Immediate publication on acceptance

- Inclusion in PubMed, CAS, Scopus and Google Scholar

- Research which is freely available for redistribution

Submit your manuscript at www.biomedcentral.com/submit

C Biomed Central 